\title{
Gold contents of Precambrian metamorphic crustal basement in Jiaodong, China and the contribution to giant gold deposits
}

ZHE XU ${ }^{1 *}$, ZAICONG WANG ${ }^{1}$, CHENG HUAI ${ }^{1}$, TAO HE $^{1}$, KEQING ZONG ${ }^{1}$, ZHAOCHU HU $^{1}$, JINGHUI GUO ${ }^{2}$ ${ }^{1}$ GPMR, School of Earth Sciences, China University of Geosciences, Wuhan 430074, China;

${ }^{2}$ Institute of geology and geophysics, China Academy of Sciences, Beijing 100029, China

*Correspondence to: zhe-xu@hotmail.com

Gold deposits in Jiaodong, eastern China define the giant gold province with an overall endowment of $>5000 \mathrm{t} \mathrm{Au}^{[1]}$. Tracing the Au source is rather important, and after studies over decades, the metasomatized mantle and crustal basement both have been proposed as the potential sources ${ }^{[2-4]}$. The gold deposits formed in about 130-120 Ma, much later than the crustal basement metamorphism of $1.9-1.8 \mathrm{Ga}^{[2]}$. Given the early-stage, high-grade metamorphism of amphibolite to granulite facies, Jiaodong Precambrian crustal basement should be so depletion of $\mathrm{Au}$ that cannot have contributed much for gold deposits ${ }^{[3,5]}$. However, previously published $\mathrm{Au}$ contents of a few ppb or even higher implied that the Precambrian crustal basement could have been the main source for the gold mineralization ${ }^{[6]}$.

In order to figure out the possible contribution of gold for the giant gold deposits, after careful sample selection and prepartion, we analyzed Au contents by analytical methods with low background in the metamorphic crustal rocks from both surface outcrops and xenoliths hosted by premineralization Mesozoic granites. The latter were not overprinted by ore-forming hydrothermal fluid and thus could better reflect the pristine feature of metal contents. Although the xenoliths contain variable sulfides, they show rather low $\mathrm{Au}$ contents $(<0.3 \mathrm{ppb}, \mathrm{n}=10)$. The rocks from surface outcrops display relatively higher Au contents (mean 0.43 $\mathrm{ppb}, \mathrm{n}=15$ ), but much lower than that of the continental crust $(1.3 \mathrm{ppb})^{[7]}$. These preliminary data indicate the high depletion of $\mathrm{Au}$ in the metamorphic crustal rocks as predicted and suggest that the Precambrian crustal basement was rather difficult as the main source for Jiaodong giant gold deposits.

[1] Deng et al. (2018) ESR. 182, 251-272. [2] Yang et al. (2014) APS. 30(9), 2447-2467. [3] Goldfarb et al. (2014) GF. 5(2), 139-153. [4] Zhu et al. (2015) SCES. 58, 1523-1537. [5] Pitcairn et al. (2006) Econ. Geol. 101, 1525-1546. [6] Yang et al. (1996) Beijing. Geol. Pub. House. [7] Rudnick and Gao. (2014) TOG. 3, 1-64. 